\title{
A Systematic Review on Information Technology Personnel's Turnover
}

\author{
Amir Hossein Ghapanchi, Ahmad Reza Ghapanchi, Amir Talaei-Khoei, and Babak Abedin
}

\begin{abstract}
This paper employs a systematic review approach to yield an insight into existing studies on the turnover of Information Systems (IS) / Information Technology (IT) personnel. Our systematic review of 72 studies from 1980 to 2009 makes implications about the background and trend of research on IS/IT turnover as well as the theories used in the literature. Based on the results of our review, we propose that the topic of IS/IT turnover has been paid a great deal of attention in recent years. After 1998 especially, there has been significant growth in the number of academic papers on the topic. Business, IS and Management discipline areas respectively have published the highest number of papers in the area. Additionally, Maslow's Hierarchy of Needs and Dual Factor Theory are two most frequently used theories in IS/IT turnover literature.
\end{abstract}

Index Terms-Intention to leave, intention to stay, IS/IT turnover, systematic review.

\section{INTRODUCTION}

The turnover rate of information system professionals (IS turnover) is one of the most persistent challenges encountered by organizations todays. Retaining IS/IT personnel is vital to organizations as they often hold tacit knowledge about how internal systems operate. IS turnover rates are in excess of $30 \%$ in some countries [1], raising serious concerns among IS practitioners and scholars. This problem worsens as the IS/IT labor market tightens due to the exponential growth of IS/IT applications in organizations and the continuing decline in the supply of IS/IT graduates [2].

Because of high demand for IS/IT skilled workers, they can easily find new jobs. Turnover creates direct recruiting and training costs for companies as well as indirect costs due to disruptions in organizational processes [3]. IS/IT professionals usually have specialized skills which makes turnover expensive. To replace an IS/IT employee, an organization has to spend from one to seven times the employee's annual salary [4]. As a result of high rates of turnover and associated costs, employers have shifted from perceiving IS/IT employees as a replaceable commodity to considering them as a valued asset [3].

This paper presents findings from our systematic review on IS/IT personnel's intention to leave an organization. A

Manuscript received August 14, 2012; revised November 9, 2012.

Amir H. Ghapanchi is with the school of ICT, Griffith University, Gold Coast, QLD, Australia. (e-mail: a.ghapanchi@griffith.edu.au).

Ahmad R. Ghapanchi is with the department of computer engineering, Isfahan University, Iran.

Amir Talaei-Khoei is with the school of Business, the University of Sunshine Coast, QLD, Australia.

Babak Abedin is with the school of Corporate Governance, Macquarie University, NSW, Australia. strong need for this paper was the fact that previous literature-based research on the topic - e.g. [1]- have not covered a comprehensive body of research published to provide a big picture of the available resources on IS/IT personnel's intention to leave.

A systematic literature review assesses and interprets all available resources relevant to a particular research topic. It seeks to provide an assessment of the literature relative to an area of research by using a systematic methodology. This research has followed [5]-[6] systematic review guidelines to reflect a big picture of IS/IT turnover research. This paper seeks to answer following research questions:

RQ1: What are demographic implications and the trend of research on IS/IT turnover?

RQ2: What are the theories applied in IS/IT turnover research?

This paper aims to help CIOs, IS human resource managers, IS managers, IS project leaders and interested researchers understand the current state of research in IT/IS turnover. Our systematic approach helps to determine where the literature has recurring themes, what trend this stream of research has followed, and where the gaps are in the existing body of knowledge.

This paper is organized as follows. Section 2 describes the method used for our systematic review. Section 3 presents results of our synthesis of the literature, including background information and trend of research followed by theories which have been used in IS/IT literature (section 4). Section 5 presents the conclusions of the research.

\section{RESEARCH METHOD}

This section describes the steps of the methodology used to perform this systematic review study. Fig. 1. shows the stages of study selection for systematic review of this paper. Systematic review is defined as a methodical way to summarize the empirical studies conducted on a topic, to identify gaps in current research or to provide background in order to justify new research. This research followed the systematic review guidelines of [5]-[6], as follows:

1) Identify the need for a systematic literature review

2) Formulate research question(s)

3) Carry out a comprehensive search for primary studies

4) Assess the quality of the studies, excluding low quality or irrelevant studies

5) Extract data from each included study

6) Summarize and synthesize study results (meta-analysis)

7) Interpret the results to determine their applicability

8) Write-up study as a report. 


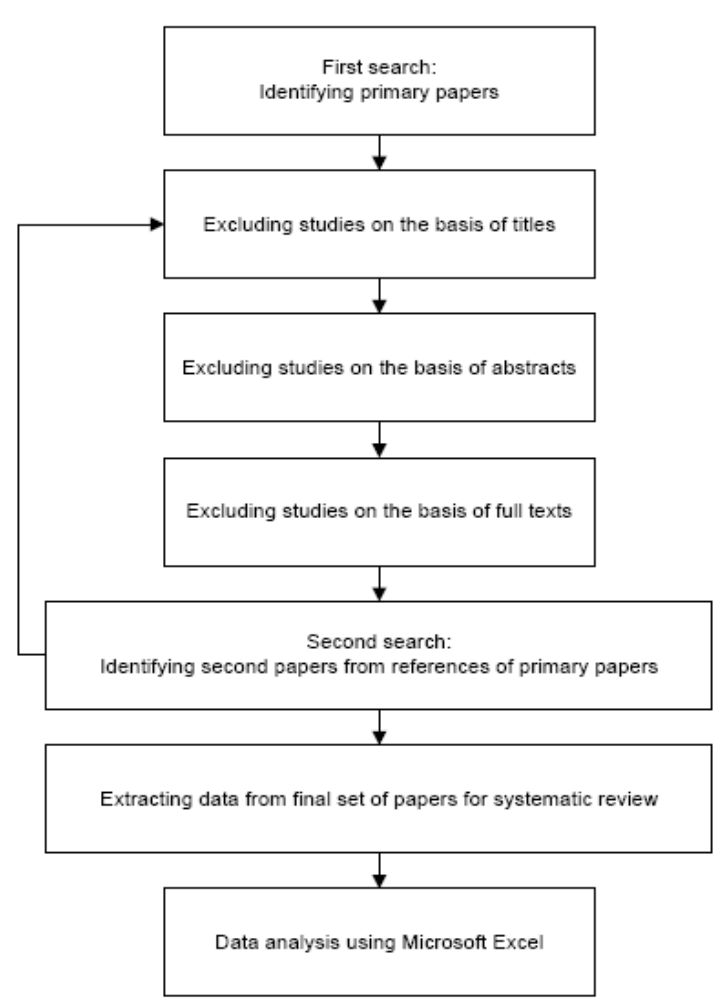

Fig. 1. Stages of the study selection process.

\section{A. Database Search}

In this section we discuss how we organized the comprehensive search for primary studies (step 3 above). The databases that included in our systematic review were: Science Direct, Business Source Premier, Inspec, Springer Link, AIS (Association for Information System) Electronic library, Scopus, ProQuest Science Journals, Google scholar, ISI Web of Science, and ACM Digital library.

In the first stage of the search of the databases, the titles, abstracts, and keywords of the journal and conference proceeding articles in the included electronic databases were searched using the following search terms:

("intention to leave" or "intention to turnover" or "intention to quit" or "intention to withdraw" or "intention to stay" or "turnover intention" or "leave intention" or "quit intention" or "stay intention" or "withdrawal intention" or "employee retention" or "employees retention" or "personnel retention" or "worker retention" or "workers retention" or "manager retention" or "managers retention" or "professional retention" or "professionals retention") and ("IS worker" or "IT worker" or "IS employee" or "IT employee" or "IS personnel" or "IT personnel" or "IS manager" or "IT manager" or "IS professional" or "IT professional" or "IS workforce" or "IT workforce")

Editorial notes, prefaces, article summaries, interviews, news, reviews, correspondence, discussions, comments, reader's letters and summaries of tutorials, workshops, panels, and poster sessions were excluded from the search. This search strategy resulted in a total of 4548 studies.

Data was extracted from all 72 (out of 4548) studies included in our systematic review using a form designed by researchers. This form enabled us to record all relevant details of the papers needed for further analysis. The form extracted data from the studies in 2 main sections: Demography (including year of publication, country, continent, affiliated department, source type (journal / conference proceeding), and source name); and Theories used by the study.

\section{RESULTS - BACKGROUND}

Fig. 2. shows the number of papers on IS/IT personnel's intention to leave each year. The number of papers has considerably increased since 1998, peaking in 2002 and 2006. It suggests that this topic has grabbed the attention of academics as well as practitioners as a major concern of organizations.

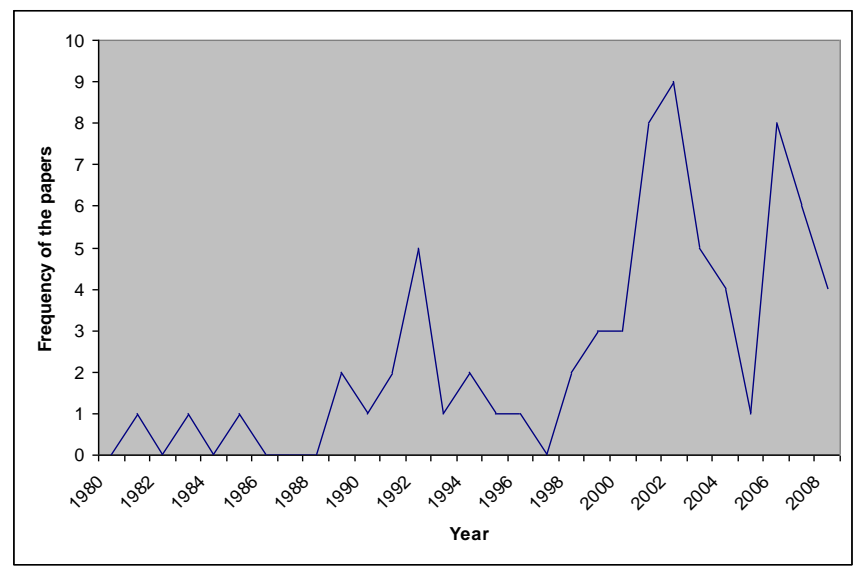

Fig. 2. Frequency of the papers per year.

Fig. 3. shows the frequency of the studies authored in different countries. The US is the most dominant country with $77 \%$ of the authors affiliated to American universities. Singapore is the next most prolific source of papers with 10 of the studies followed by Canada with 3. Additionally as Fig. 3. suggests, the North America continent is dominant in the research on IS turnover (83\%) followed by Asia (15\%).

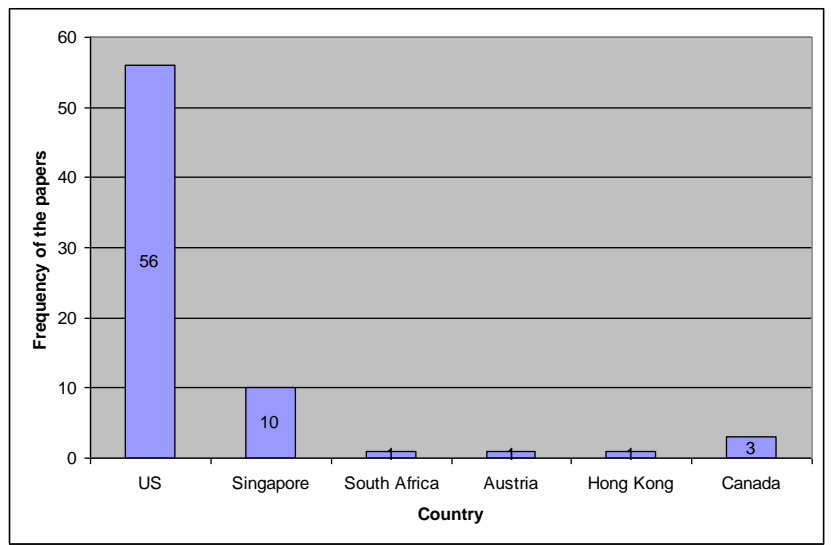

Fig. 3. Frequency of the papers per countries.

The studies on IS turnover have been produced in different academic departments. As Fig. 4 proposes, the Business department is dominant with 32 papers out of 72 followed by the IS department with 24 papers and the Management department with 12 papers. The reason is that IS is a young field of study and IS research used to be conducted in the business and management departments before establishment of IS departments. 


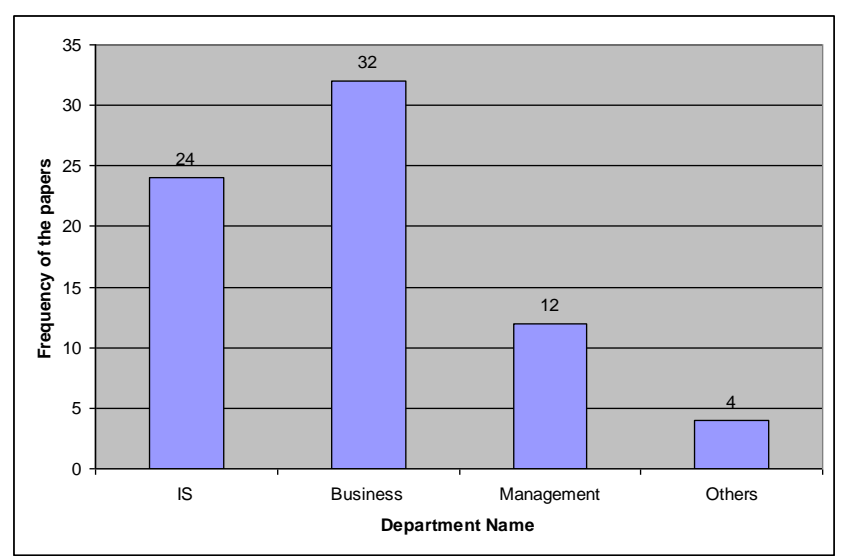

Fig. 4. Frequency of the papers based on academic department.

As was discussed in section 2, our source of material for systematic review includes peer-reviewed journal as well as conference proceeding papers. Among 72 papers found, 46 are journal papers and 26 are conference proceeding papers. About half of the papers are published in highly prestigious IS journals: 11 are published in Information \& Management, 7 in MIS Quarterly, 6 in Journal of Management Information Systems, 4 in Communications of the ACM, and 3, 2 and 2 respectively in the Database for Advances in Information Systems, Information System Research, and Journal of Computer Information Systems.

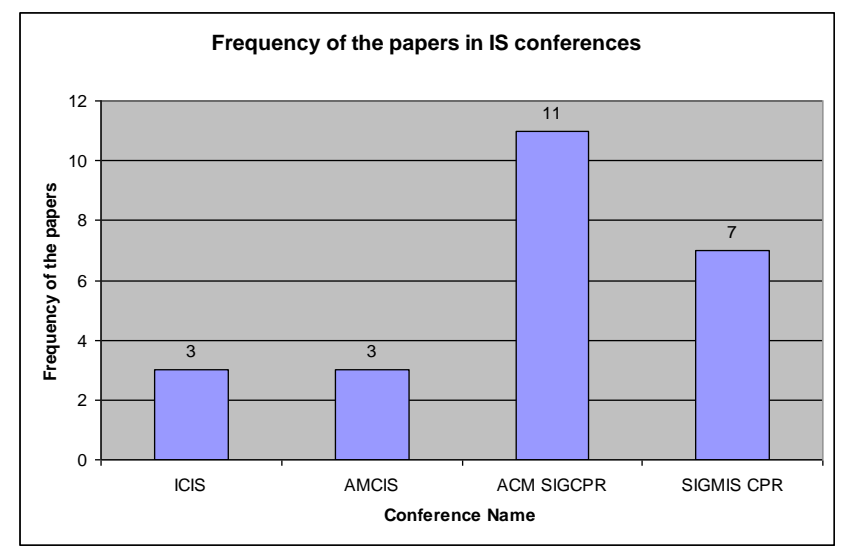

Fig. 5. Frequency of the papers in IS conferences.

With regard to papers in conference proceedings, ACM SIGCPR is dominant in publishing on IS turnover with 11 papers out of 72 followed by SIGMIS CPR with 7 papers. ICIS and AMCIS are in equal third place with 3 published papers each (see Fig. 5.).

\section{RESUlTS - THEORIES USED}

In this section we briefly overview the major turnover theories in the extant IS turnover literature. About $40 \%$ of paper (29 out of 72) studied in this research have used at least one theory. In total, 38 different theories have been applied, used, or at least mentioned in our materials for systematic review. Among them, Maslow's Hierarchy of needs and Dual Factor Theory have been used more frequently ( 5 and 4 times respectively). There are also 8 other theories which have been used 2 times: (Social) Exchange Theory, Person-to-Organization Fit Theory, Discrepancy Theory, Attribution Theory, Job Characteristics Theory, Theory of Needs, and Theory of X and Y. The other 27 theories have been mentioned only once. In the rest of this section, we provide a brief introduction to each of the theories which has been mentioned, used, or applied at least twice in the extant literature on IS turnover.

Maslow's Hierarchy of Needs. In Maslow's hierarchy of needs [7] five hierarchical needs are identified: physiological, safety, social, esteem, and self-actualization. If there is a significant unmet need that could be satisfied by changing the job, the worker is likely to leave the current company and switch to a better company. Consequently, it is very important for companies to align career incentives with employee needs to lower their turnover rate.

Dual Factor Theory. Herzbero et al. [8] claimed that humans have two sets of needs: the need as an animal to keep away from pain, and the need as a human being to grow psychologically. In other words, fulfilling an employee's motivation and hygiene could lower the chance of turnover.

Social Exchange Theory. Employees tend to form social exchange relationships with others so long as they feel they are receiving benefits out of that [9].

Person-to-Organization Fit Theory. This theory acknowledges that high rate of compatibility between an employee and an organization could negatively affect his/her chance of turnover [10].

Discrepancy Theory. This theory advocates the need to consider individual differences [11]. According to this theory, job satisfaction depends on the match between job outcomes (e.g. salary and reward) and those desired by the employee. The closer the match between job outcomes and an employee's job expectations, the more the job satisfaction. Also, a large discrepancy could lead to a lower job satisfaction and a small discrepancy could result in a higher job satisfaction.

Attribution Theory. This theory acknowledges that an employee's attribution for a negative event such as image violation or work exhaustion could build a basis for his/her decisions about how to stop it [12].

Job Characteristics Theory. This theory tells that job characteristics such as task variety, task significance, feedback, and autonomy encourage employees to show a behavior that leads to positive organizational outcomes [13].

Theory of Needs. This theory posits that when an employee's needs (e.g. affiliation, achievement and power needs) are met at an organization, turnover is lower [14].

Theory of $\mathbf{X}$ and $\mathbf{Y}$. In fact this is two theories, they are theories of human motivation developed by Douglas McGregor at the MIT Sloan School of Management that have been used in organization studies like human resource management (HRM), and organizational development. They explain two very different attitudes toward employees' motivation [15]. The theory posits that a company follows either first or the second approach. Theory $\mathrm{X}$ posits that management assumes that employees are inherently lazy and tend to avoid work if they can. As a result, they need to be supervised and a control system should be developed. Theory $\mathrm{Y}$ acknowledges that managers think that, given the right conditions, most of employees incline to do their job well.

Human Capital Theory. This theory acknowledges that employees' education and experience render them more marketable, and as a result more able to turnover [16]. 


\section{Conclusions}

This study reports a systematic review of the literature on IS/IT turnover. Based on the results of our systematic review, we note that the topic of IS turnover have received increased attention in recent years. Specially, after 1998 we see a huge growth in the number of academic papers on the topic. Moreover, most of the research on IS turnover has been done in US followed by Singapore. Business, IS, and Management are respectively the departments with the highest number of papers in the area. In terms of theories, Maslow's Hierarchy of Needs and Dual Factor Theory are two more often used theories in our set for systematic review.

\section{REFERENCES}

[1] D. Joseph, N. K. Yee, C. Koh, and S. Ang, "Turnover of information technology professionals: A narrative review, meta-analytic structural equation modeling, and model development," MIS Quarterly, vol. 31, no. 3, pp. 547-577, 2007.

[2] D. E. Hecker, "Occupational Employment Projections to 2014," Monthly Labor Review, vol. 128, no. 11, pp. 70-101, 2005.

[3] J. B. Thatcher, L. P. Stepina, and R. J. Boyle, "Turnover of Information Technology Workers: Examining Empirically the Influence of Attitudes, Job Characteristics, and External Markets," Journal of Management Information Systems, vol. 19, no. 3, pp. 231-261, 2003

[4] J. Kochanski, "How to keep me-Retaining technical professionals," Research Technology Management, vol. 44, no. 3, pp. 31-39, 2001.

[5] B. Kitchenham, "Procedures for Performing Systematic Reviews," Keele University and National ICT Australia Ltd, 2004, pp. 1-28.

[6] B. Kitchenham and E. Mendes, "A Systematic Review of Cross- vs. Within-Company Cost Estimation Studies," in Proc. of 10th International Conference on Evaluation and Assessment in Software Engineering, Keele University, Staffordshire, UK, 2006, pp.89-98.

[7] A. H. Maslow, Motivation and Personality, Harper \& Row, New York, 1987.

[8] F. Herzbero, B. Mausner, and B. B. Snyderman, The Motivation to Work (Second Edition), New York: John Wiley and Sons, 1959.

[9] R. Cropanzano, D. Rupp, and Z. Byrne, "The Relationship of Emotional Exhaustion to Work Attitudes, Job Performance, and Organizational Citizenship Behaviors," Journal of Applied Psychology, vol. 88, no. 1, pp. 160-169, 2003.

[10] C. Argyris, "The individual and organization: Some problems of mutual adjustment," Administrative Science Quarterly, vol. 2, pp. 1-24, 1957.

[11] E. A. Locke, The nature and causes of job satisfaction, In E. Dunnett (ed.). Handbook of Industrial and Organizational Psychology. Chicago Rand McNally, pp. 1297-1350, 1976.

[12] H. H. Kelley, "The process of causal attribution," American Psvcholonist, vol. 28, no. 2, pp. 107-128, 1973.

[13] M. L. Ambrose and C. T. Kulik, "Old Friends, New Faces: Motivation Research in the 1990s," Journal of Management, vol. 25, no. 3, pp 231-292, 1999

[14] D. McClelland, The achieving society, Princeton: Van Nostrand, 1961.

[15] D. McGregor, The Human Side of Enterprise, McGraw-Hill, New York, NY, 1960

[16] G. Becker, Human Capital, University of Chicago Press, Chicago, 1975.

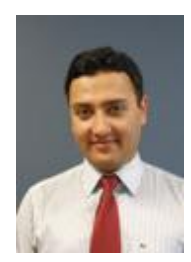

Amir Hossein Ghapanchi obtained his $\mathrm{PhD}$ in Information Systems from the University of New South Wales, Sydney. Prior to this, he completed his Master degree in IT Engineering at Tarbiat Modares University, Tehran. He also holds a Bsc in Industrial Engineering from Isfahan University of Technology, Isfahan Currently, he is a lecturer at the School of Information and Communication Technology, Griffith University, Australia. Amir has served in several national information system projects. His main research interests include health informatics, the management of open source software projects, e-government planning and implementation, and multi-criteria decision making (MCDM). Amir has published in several prestigious management and information system journals such as International Journal of Project Management, Journal of Systems and Software, International Journal of Information Management, and Electronic Markets. Amir has been an active member of the Institute for Integrated and Intelligent Systems (IIIS) and Asia-Pacific ubiquitous Healthcare Research Centre (APuHC).

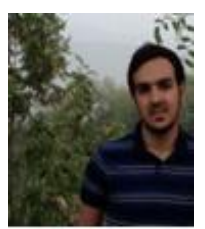

Ahmad Reza Ghapanchi was born on February 24 1991 at Isfahan, Iran. He has been doing a bachelor study in computer engineering (software) at Isfahan University since 2009. Prior to that, he has been studying mathematics. Ahmad has got a very high rank in Iranian National University Entry Exam. He has done his industrial project at Metako. Ahmad has also been involved in several software projects. His research interests include software engineering, network management, programming, as well as soft aspects of information technologies such as information system adoption and evaluation.

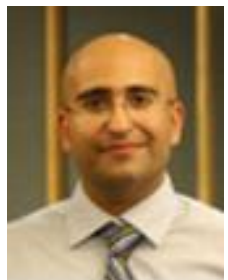

Amir Talaei-Khoei received his $\mathrm{PhD}$ from the University of New South Wales (UNSW) in Australia and holds a Master of Science of Information Technology from the Royal Institute of Technology $(\mathrm{KTH})$ in Sweden. Prior to joining academia, Amir was involved in industrial e-health projects. Dr. Talaei-Khoei has taught for ICT, Software Engineering, Information Systems, MBA and Executive MBA programs in Australia and Europe. $\mathrm{He}$ is a faculty member at University of the Sunshine Coast. Since 2008, he has been an active member of Asia-Pacific ubiquitous Healthcare Research Centre (APuHC). As a part of the research at APuHC, he has been involved in different national and international projects in ehealth. Amir was a member of the research board for developing the scoping document of the long term strategic IT plan for Aged Care Industry IT Council (ACIITC) in Australia. Dr Talaei-Khoei's research mainly focuses on software agents, computer supportive cooperative work and game technologies in healthcare scenarios. He was born in 1982 in Iran.

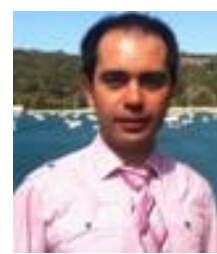

Babak Abedin has received his $\mathrm{PhD}$ in Information Systems from the University of New South Wales in Sydney, Australia. Prior to this, he completed his Master degree in IT Management at the University of Tehran and did his Bachelor in Industrial Engineering at Iran University of Science and Technology, both in Iran. He is currently an information systems lecturer and a ACG postgraduate coordinator at Faculty of Business and Economics at Macquarie University in Sydney. His research interests are e-learning, Social Media, and E-commerce and has published extensively in various journals in these areas. 